\title{
CHARACTERIZATION OF THE INTERFACE BETWEEN FRESH CONCRETE AND FORMWORK
}

\author{
Samir BOUHAROUN \\ Laboratoire Génie Civil et géo-Environnement (LGCgE) - Lille Nord de France (EA 4515), \\ IUT de Béthune, 1230 Rue de l'Université, F-62400 Béthune, France
}

Received 03 Oct 2012; accepted 26 Feb 2013

\begin{abstract}
Concrete surface quality is generally linked to the development conditions of concrete close to the formwork. This work aims to study the influence of the nature of release agent and the quantity of fine elements on the chemical interactions at the concrete/oil/formwork interface. Five concretes were prepared at 28, 30, 32, 34, and 36\% of paste to study the influence of paste volume on the friction between formwork and fresh concrete. The friction tests were performed using an apparatus which can reproduce the same conditions of construction sites. In addition, a physicochemical investigation was achieved to identify the effect of fine elements on the ability to form the interstitial mediums at the interface. The formation of soap in the vicinity of the formwork surfaces was also studied as a function of the content and the nature of oils. The results showed that the friction between fresh concrete and formwork depends on the pore solution content present at the interface.
\end{abstract}

Keywords: release agent, paste volume, friction, formation of soap, chemical interactions.

\section{Introduction}

The characterization of fresh concrete on construction sites is still typically limited to use of a single parameter, workability, which is presumed to describe the behaviour of fresh concrete. Good workability reduces the risk of defects and improves the final quality of structures (Amziane et al. 2005; Ferraris, De Larrard 1998; Laskar, Talukdar 2009). The workability of concrete is strongly linked to the paste volume for concretes without superplasticizers. As an active element in concrete, the paste is unique in that it can fill the voids in the granular skeleton as well as act as a lubricant (Ferraris 1999; De Larrard et al. 1998). However, the movement of aggregates is limited by intergranular friction forces and friction forces against formwork and pumping pipes (De Larrard 1999; Koehler 2004; Kwon et al. 2011).

Currently, there are many gaps in the understanding of the phenomena that take place when concrete is poured into formwork. Some of these phenomena are directly related to the friction between the materials in contact. The friction at the concrete/formwork interface can be considered a favourable factor that reduces lateral pressure exerted on the formwork, but it can also be unfavourable to the quality of the concrete surfaces (Proske et al. 2010; Graubner et al. 2012; Libessart 2006; Kwon et al. 2011). Some studies have reported on the effect of friction on formwork pressure. Proske (2007) modelled the friction effect based on the friction coefficient increasing over time. Vanhove (2001) also analysed the effect of formwork friction based on the friction coefficient. He measured the friction using a tribometer specially designed for a complex medium such as fresh concrete, in which the friction coefficient is known to be dependent on the roughness of the formwork surface. There are many factors that influence the behaviour at the interface, such as the mixture proportions, admixtures, temperature, the casting rate and the height of the formwork. Those factors can be classified as intrinsic or extrinsic. Intrinsic factors are related only to material characteristics, while extrinsic factors are such things as formwork flexibility, wall roughness, and external temperature (Ngo et al. 2010, 2011; Kwon et al. 2011). However, these studies do not take into account the chemical interactions that occur at the interface between fresh concrete and formwork.

Indeed, to obtain a high-quality concrete surface, release agents are applied to formwork to prevent sticking or adhering of formwork walls to hardened concrete. These release agents are usually used to facilitate the removal of concrete elements and produce a concrete surface with good aesthetic qualities. These products are also used to protect the formwork surfaces from corroding and to facilitate their cleaning (Courarda et al. 2012, 2011; Thompson 1969; Gram 2004; Hart 1994).

Corresponding author: Samir Bouharoun

E-mail:samir_bouharoun@yahoo.fr 
In context in which sustainable development has become a major priority, the construction field must face new environmental requirements. Particular concerns are related to the poorly biodegradable mineral release agents that are currently used as to separating fresh concrete from formwork surfaces. The nature of this oil creates significant environmental pollution risks. New formulations of release agents of vegetable origin have been developed. The main advantages of vegetable oil products over mineral oil-based release agents are the following: no emissions of volatile organic compounds, no pungently unpleasant smell, non-irritating to people's skin, non-flammable, biodegradable in the environment, a renewable source, reduced insurance, storage and waste treatment and disposal costs and a "greener" public image for the industry (Baty, Reynolds 1997; De Brito et al. 2000). However, the use of vegetable oil-based release agents requires sufficient knowledge of their behaviour at the concrete/release agent/formwork interface.

Several studies have been conducted to examine the interface mechanisms in the presence of vegetable oils. Recently, researchers have shown that two separate phenomena occur at the concrete/oil/wall interface (Courarda et al. 2011; Libessart 2006; Bouharoun 2011). Mineral oil-based release agents act by physically separating the concrete from the formwork wall, while vegetable oilbased release agents have both a chemical effect and a physical effect on the interface. This paper discusses the influence of paste volume and the nature of the release agent on the physicochemical properties at the interface and the resulting friction between the concrete and the formwork. To examine this influence, fives ordinary concretes of different paste volumes were formulated. A detailed study on the friction at the concrete/formwork and concrete/oil/formwork interfaces was performed using a plan/plan tribometer. Characterization tests of the concrete/oil and oil/formwork interfaces were then performed to better understand the mechanisms of the oil formulations as a function of their composition. The results showed that the interface friction stress depends on the volume of paste and the nature of the release agent. In addition, this study highlights the impact of soap quantity on interface mechanisms.

\section{Materials}

\subsection{Binder characteristics}

The cementitious material used in the mixtures studied was an ordinary Portland cement (CEM I 52.5 type N according to NF EN 197-1). Chemical analysis of the clinker provided by the manufacturer revealed that the cementitious material was $64.3 \% \mathrm{CaO}, 19.2 \% \mathrm{SiO}_{2}$, $5.1 \% \mathrm{Al}_{2} \mathrm{O}_{3}, 3.4 \% \mathrm{SO}_{3}, 2.9 \%, \mathrm{MgO}, 2.5 \% \mathrm{Fe}_{2} \mathrm{O}_{3}, 0.7 \%$ $\mathrm{K}_{2} \mathrm{O}$, and $0.3 \% \mathrm{Na}_{2} \mathrm{O}$. The Blaine surface area of the cement was $4000 \mathrm{~cm}^{2} / \mathrm{g}$, and the density was $3.09 \mathrm{~g} / \mathrm{cm}^{3}$.

The limestone filler used was BETOCARB-MQ, which is essentially composed of carbonate (99.3\%).

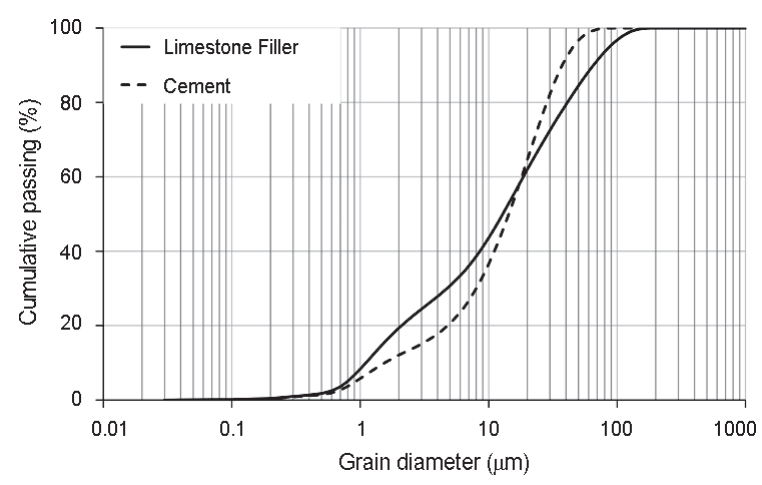

Fig. 1. Grain size distributions of cement and limestone filler

This limestone filler is characterized by a Blaine fineness of $3970 \mathrm{~cm}^{2} / \mathrm{g}$, a density of $2.71 \mathrm{~g} / \mathrm{cm}^{3}$ and a water content of $0.1 \%$.

Figure 1 shows the gradation curves of the cement and limestone filler as measured using a laser granulometer.

The key point that emerges from the gradation results is the greater fineness of the limestone filler compared to that of the cement. The following observations can be made based on the gradation curves:

- $90 \%$ of particles have a diameter less than or equal to $37.4 \mu \mathrm{m}$ for cement and $66 \mu \mathrm{m}$ for limestone filler;

- $50 \%$ of particles have a diameter less than or equal to $14.3 \mu \mathrm{m}$ for cement and $13.5 \mu \mathrm{m}$ for limestone filler;

- $10 \%$ of particles have a diameter less than or equal to $1.6 \mu \mathrm{m}$ for cement and $1.2 \mu \mathrm{m}$ for limestone filler.

\subsection{Aggregate properties}

The characteristics of the aggregates used are given in Table 1.

Sand and two types of crushed gravels were used to produce the concretes. To obtain a formulation corresponding to the standard specifications, characterization tests were performed. These tests concern the absolute and apparent densities, the cleanliness (sand equivalent), the absorption coefficient and the sand-size gradation.

The results obtained show that the sand is very clean and can be used without risk of detrimentally altering the composition of concrete. The fineness modulus (Fm) of the sand was equal to 2.51 . This fineness modulus was

Table 1. Aggregate characteristics

\begin{tabular}{lccc}
\hline Aggregates & Sand & $\begin{array}{c}\text { Gravel } \\
1\end{array}$ & $\begin{array}{c}\text { Gravel } \\
2\end{array}$ \\
\hline Granular class & $0 / 4$ & $4 / 8$ & $8 / 12.5$ \\
\hline Apparent density $\left(\mathrm{g} / \mathrm{cm}^{3}\right)$ & 1.49 & 1.42 & 1.45 \\
\hline Absolute density $\left(\mathrm{g} / \mathrm{cm}^{3}\right)$ & 2.57 & 2.72 & 2.6 \\
\hline Absorption coefficient $(\%)$ & 0.8 & - & - \\
\hline Sand equivalent $(\%)$ & 97.38 & - & - \\
\hline
\end{tabular}




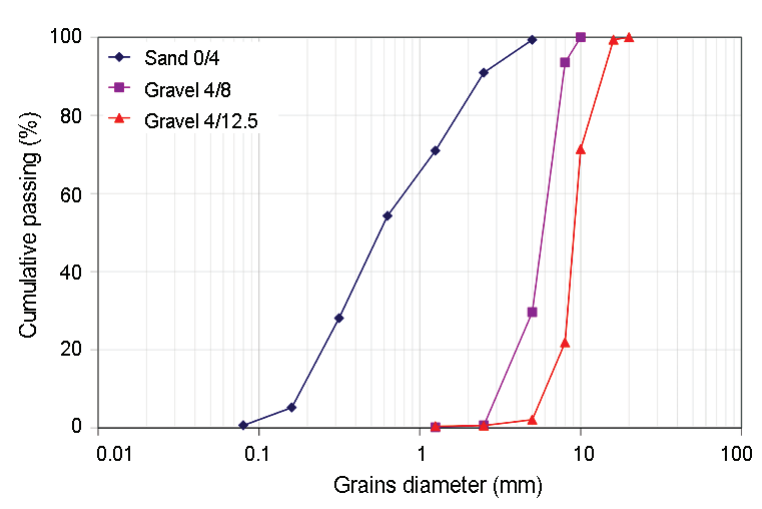

Fig. 2. Grain size distributions of coarse and fine aggregates

derived from the gradation curve shown in Figure 2. Particles less than $80 \mu \mathrm{m}$ make up $0.6 \%$ of this sand.

\subsection{Formulation of concretes}

The effect of paste volume was studied by formulating five ordinary concretes with $28,30,32,34$ and $36 \%$ paste. These concretes were identified as C28, C30, C32, $\mathrm{C} 34$ and C36, respectively. The water/binder ratio (w/b) and aggregate/sand ratio $(\mathrm{a} / \mathrm{s})$ were held constant. Table 2 shows the formulation and properties of the concretes used in this study.

The concrete was mixed from dry materials according to NF EN 12350-2 (1999). A rest time of $10 \mathrm{~min}$ was allowed for absorption of water by the aggregates. This precaution avoids an alteration of the rheological properties of the concrete a few minutes after mixing. The mixer used to prepare the concretes was a DZ120 V DIEM. It was equipped with several blades to optimize the mixing. A slump test of each mix was conducted to check the workability of the concretes.

The yield stress and the plastic viscosity of each concrete were measured using the ICAR rheometer. This device is portable on constructions site; it was developed

Table 2. Composition and properties of concretes

\begin{tabular}{lccccc}
\hline & C28 & C30 & C32 & C34 & C36 \\
\hline Paste volume $(\%)$ & 28 & 30 & 32 & 34 & 36 \\
\hline Limestone filler $\left(\mathrm{kg} / \mathrm{m}^{3}\right)$ & 77 & 83 & 88 & 94 & 99 \\
\hline Sand 0/4 $\left(\mathrm{kg} / \mathrm{m}^{3}\right)$ & 838 & 815 & 792 & 768 & 744 \\
\hline Aggregate $4 / 8\left(\mathrm{~kg} / \mathrm{m}^{3}\right)$ & 287 & 279 & 271 & 263 & 255 \\
\hline Aggregate & 778 & 756 & 734 & 712 & 690 \\
\hline 8/12.5 $\left(\mathrm{kg} / \mathrm{m}^{3}\right)$ & 176 & 189 & 201 & 214 & 228 \\
\hline Water $\left(\mathrm{kg} / \mathrm{m}^{3}\right)$ & 232 & 248 & 265 & 282 & 301 \\
\hline Cement $(\mathrm{C})\left(\mathrm{kg} / \mathrm{m}^{3}\right)$ & & & 0.57 & & \\
\hline Water/binder ratio & & & 1.27 & & \\
\hline Crushed aggregate/sand & 120 & 130 & 140 & 150 & 170 \\
\hline Slump $(\mathrm{mm})$ & 1.9 & 1.9 & 2 & 2 & 2 \\
\hline Air content $(\%)$ & 30.1 & 25.3 & 21.1 & 16.7 & 12.5 \\
\hline Plastic viscosity $(\mathrm{Pa} \cdot \mathrm{s})$ & 549.1 & 502.3 & 429.9 & 355.4 & 263.2 \\
\hline Yield stress $(\mathrm{Pa})$ & & & & \\
\hline
\end{tabular}

at the University of Texas (Koehler 2004; Koehler et al. 2006). For each concrete mixture, the protocol test begins with a pre-sheared, followed by a rest period so that the concrete can be completely restructured. The concrete is then sheared at a velocity of $3.14 \mathrm{rad} / \mathrm{s}$ during $20 \mathrm{~s}$ to obtain a complete breakdown of the material. Then, a ramped down from $3.14 \mathrm{rad} / \mathrm{s}$ to $0.314 \mathrm{rad} / \mathrm{s}$, by steps of $0.0684 \mathrm{rad} / \mathrm{s}$ is applied.

\subsection{Release agents}

To assess the influence of oil type on the interface friction, two commercially available release agents, one of mineral origin and one of vegetable origin, were used. The properties of the oils are given in Table 3 .

Table 3. Characteristics of the release agents

\begin{tabular}{lcc}
\hline Nature of oil & Vegetable oil & Mineral oil \\
\hline Reference & $\mathrm{Hv}$ & $\mathrm{Hm}$ \\
\hline Color & yellow & yellow \\
\hline Flash point $\left({ }^{\circ} \mathrm{C}\right)$ & $>100$ & $>100$ \\
\hline Acid number $(\mathrm{mg} \mathrm{KOH} / \mathrm{g})$ & 5.4 & 1 \\
\hline Hydroxide number $(\mathrm{mg} \mathrm{KOH} / \mathrm{g})$ & 1 & 0.85 \\
\hline Density & 0.93 & 0.86 \\
\hline Viscosity $(\mathrm{mPa} \cdot \mathrm{s})$ & 66.6 & 24.5 \\
\hline
\end{tabular}

$\mathrm{Hm}$ is a pale yellow, liquid, ready-to-use, de-layedrelease agent. It contains a primary mineral base as well as an acidifier and an anti-corrosion agent (the latter was not considered in this study). This oil, which is composed of hydrocarbons, has low biodegradability and can therefore cause water pollution in the environment.

$\mathrm{Hv}$ is a straw-yellow, liquid, ready-to-use delayedrelease agent. In addition to the vegetable ester base, it contains an acidifier and a solvent. Note that the acid number values of the $\mathrm{COOH}$ carboxylic functions in Table 3 corresponding to non-saponified fatty acids.

To prevent an oil surplus and ensure a good oil distribution on the plate, the release agents were sprayed by an Eco-spray sprayer at $20 \mathrm{~cm}$ from the tribometer plate.

\section{Experimental methods}

\subsection{Measurement of friction}

The principle of this device was inspired by the box shear apparatus used in soil mechanics (Fig. 3). It can reproduce the conditions encountered by manufacturers of concrete walls and precast elements. In particular, it can create sliding contacts between concrete, release agent and formwork (Vanhove 2001).

Two 120-mm-diameter cylinders, with concrete inside, were placed on either side of a metal plate. The sample holders were fitted with a gasket system to prevent water ingress. The plate was set in motion using a motor coupled to an endless screw. The plate travel was $800 \mathrm{~mm}$. The concrete was pressed against the plate by a jack. 


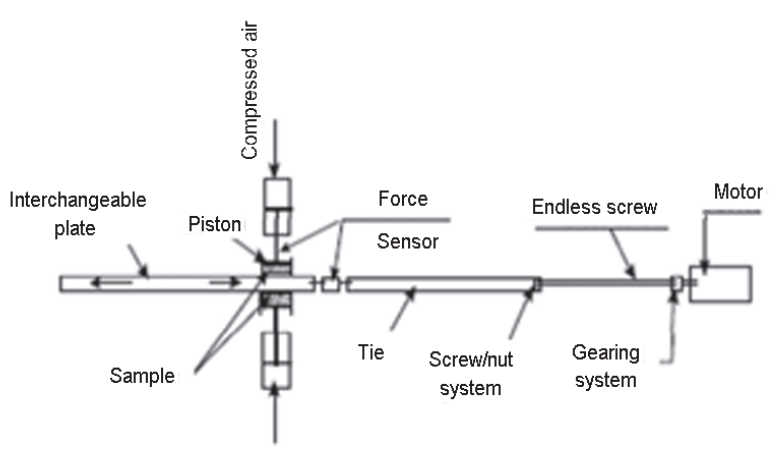

Fig. 3. Friction device (Vanhove 2001)

The parameters for this experimental study were chosen according to the jobsite conditions. After mixing, the concrete was placed in the sample holders. The normal pressure was increased incrementally until the final setting state (Proske 2007; Graubner et al. 2012).

The magnitude of the load increment depended on the casting rate. In the friction tests, the applied vertical stresses were normally $30 \pm 2,50 \pm 2,70 \pm 2$, and $90 \pm 2 \mathrm{kPa}$, which correspond to lateral pressures applied by the concrete on formwork 1.2 and $3.6 \mathrm{~m}$ in height (Fig. 4).

A displacement of $2.5 \mathrm{~mm}$ with a pull-out velocity of $5 \mathrm{~mm} / \mathrm{min}$ was applied to the metallic plate at every load step. The selected velocity simulates the vertical displacement of the concrete after placement in real formwork. The frictional, or tangential, stress was calculated by the following equation for each load step:

$$
\tau_{f}=\frac{F_{m e s}-F_{p a r}}{S c} .
$$

$F_{p a r}$ is the resultant of the parasitic frictional forces due to the watertight system against the plate. The area in contact between the concrete and the plate is calculated from the diameter of the sample holder. In this study, this area was $S_{c}=113.1 \mathrm{~cm}^{2}$.

The friction coefficient was calculated using Eqn (2).

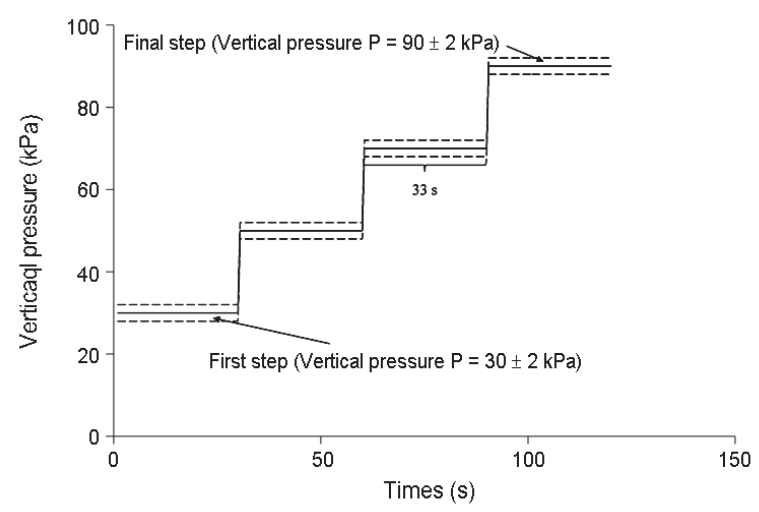

Fig. 4. Experimental protocol

$$
\mu=\frac{\tau_{f}}{P},
$$

where $\mu$ and $P$ represent the friction coefficient and the lateral pressure applied to the fresh concrete, respectively.

\subsection{Loss of oil film thickness}

The oil film thickness is measured after passing of the fresh concrete on the metallic plate to determine the amount of oil involved in the formation of emulsified mediums close to the formwork wall by the weighing method. This technique is easy and has been validated by Libessart (2006) by comparison with PIXE techniques. Weighings were performed with a scale of $0.001-\mathrm{g}$ accuracy. The film thickness (e) is calculated for a circular sample $3 \mathrm{~cm}$ in diameter cut from a real formwork wall, using the following equation:

$$
e=\frac{m_{h}-m_{s}}{\rho_{h} \times S_{p}},
$$

where: $\rho_{h}$ and $S_{p}$ are the density of the oil and the surface of the circular sample of formwork; $m_{s}$ and $m_{h}$ represent the dry and oiled weights, respectively of the tablet dry weight of the circular sample of formwork before or after passing of fresh concrete.

Measurement of the thickness of the oil film was carried out before and after passing of fresh concrete on the metal plate for each contact pressure, to calculate the reduction rate of the oil film thickness $(\% R)$ after concrete passing (Eqn (4)):

$$
\% R=\frac{e_{f}}{e_{i}} \times 100,
$$

where: $e_{i}$ is the initial thickness of the oil film (before passing of the fresh concrete); and $e_{f}$ is the final thickness of the oil film (after passing of the fresh concrete).

\subsection{Recovery of pore solution}

After the concrete was poured into the sample holders, an interstitial medium formed at the concrete/oil/formwork interface where the pore solution of the fresh concrete was in contact with the release agent (De Brito et al. 2000; Gram 2004; Courarda et al. 2011). This interface is very complex. The quantities of oil and pore solution at the concrete/oil/formwork interface must be known to understand the friction mechanisms near the formwork. To determine the composition of the interstitial mediums at the interface, the pore solution that migrated to the interface under the influences of pressure and concrete vibration were collected and weighted. A cylindrical sample holder of a tribometer, a plate and a perforated disc with a mesh screen of $80 \mu \mathrm{m}$ and two lids were used in this step (Fig. 5). The surface of the perforated disc was $S_{d}=113.04 \mathrm{~cm}^{2}$. 


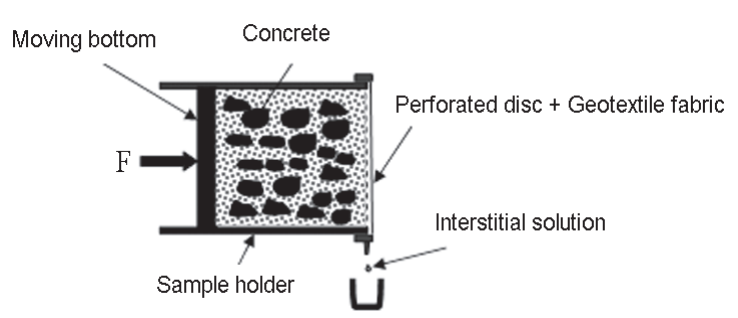

Fig. 5. Experimental device for the recovery of pore solution

The goal of the method is to introduce the fresh concrete in three layers in the lightly oiled sample holder for friction tests. After 30 seconds of friction, the pore solution at the interface was collected in a container to be weighed by a balance with $1 / 1000$-g precision. The quantity of pore solution present at the interface was measured for each contact pressure. The results are expressed in terms of grams at the surface of contact concrete/plate.

After recovering the pore solution from the fresh concrete, $\mathrm{pH}$ measurements were performed using a $\mathrm{pH}$ meter, to examine the variation in $\mathrm{pH}$ as a function of time. The results showed that pore solution is basic and that its $\mathrm{pH}$ is constant regardless of the paste volume. The $\mathrm{pH}$ values measured were between 12.7 and 13.1.

\subsection{Reconstitution of interstitial mediums}

Medium models were prepared with oil contents (Hv or $\mathrm{Hm}$ ) of 2, 5, 8, 11, 14, 17 and 20\%, combined with 98 , $95,92,89,86,83$, and $20 \%$ concrete pore solutions (PS). $10 \mathrm{ml}$ of each interstitial medium were prepared, stirred, and left to rest for $5 \mathrm{~min}$ before each measure.

For each release agent, seven interstitial mediums were reconstituted at different oil content. Therefore, 35 interstitial mediums were formulated with different percentage of oils and pore solutions. Table 4 shows the interstitial mediums prepared in the case of this study.
It is important to remember that the interstitial medium is composed of pore solution and solubilized hydrophilic compounds, such as the oil film on the wall and soaps formed at the interface.

\subsection{Measurement of contact angle and surface tension}

A PG-X goniometer was used in this study to determine the contact angle and the surface tension of liquids. This apparatus measures the contact angle at the interface between a liquid drop and the substrate surface on which it is placed. Testing with the PGX is effortless. One simply places the unit on top of a sample and presses the PUMP button. The instrument automatically pumps out a droplet, captures the liquid/substrate interaction and graphs the results. The tests were carried out on pore solutions of fresh concrete and reconstituted interstitial medium. The contact angles and surface tensions were measured on a metal plate with the same characteristics as the formwork walls.

\subsection{Quantification of soap formation}

The formation of soaps is a process that governs the properties of the interstitial medium and thus induces a chemical action during the formwork removal operation. However, the phenomena involved have not been precisely described in the literature. Therefore, it seems necessary to provide additional data on this subject. The formation of calcium soap is a chemical effect that occurs by saponification between ester and calcium hydroxide or by salification of fatty acids at the concrete/ formwork interface in a basic medium $(\mathrm{pH} \geq 7)$ (Libessart 2006; Baty, Reynolds 1997; Hart 1994).

Soaps are carboxylates of calcium and more specifically the salts of fatty acids, which have two origins in this case:

- A free fatty acid added to the formulation as an acidifier, which, in basic medium, turns into a fatty acid salt through salification:

Table 4. Interstitial mediums (PS: Pore solution)

\begin{tabular}{ccccc}
\hline $\mathrm{C} 28$ & $\mathrm{C} 30$ & $\mathrm{C} 32$ & $\mathrm{C} 34$ & $\mathrm{C} 36$ \\
\hline $2 \% \mathrm{Hv}+98 \% \mathrm{PS}$ & $2 \% \mathrm{Hv}+98 \% \mathrm{PS}$ & $2 \% \mathrm{Hv}+98 \% \mathrm{PS}$ & $2 \% \mathrm{Hv}+98 \% \mathrm{PS}$ & $2 \% \mathrm{Hv}+98 \% \mathrm{PS}$ \\
\hline $5 \% \mathrm{Hv}+95 \% \mathrm{PS}$ & $5 \% \mathrm{Hv}+95 \% \mathrm{PS}$ & $5 \% \mathrm{Hv}+95 \% \mathrm{PS}$ & $5 \% \mathrm{Hv}+95 \% \mathrm{PS}$ & $5 \% \mathrm{Hv}+95 \% \mathrm{PS}$ \\
\hline $8 \% \mathrm{Hv}+92 \% \mathrm{PS}$ & $8 \% \mathrm{Hv}+92 \% \mathrm{PS}$ & $8 \% \mathrm{Hv}+92 \% \mathrm{PS}$ & $8 \% \mathrm{Hv}+92 \% \mathrm{PS}$ & $8 \% \mathrm{Hv}+92 \% \mathrm{PS}$ \\
\hline $11 \% \mathrm{Hv}+89 \% \mathrm{PS}$ & $11 \% \mathrm{Hv}+89 \% \mathrm{PS}$ & $11 \% \mathrm{Hv}+89 \% \mathrm{PS}$ & $11 \% \mathrm{Hv}+89 \% \mathrm{PS}$ & $11 \% \mathrm{Hv}+89 \% \mathrm{PS}$ \\
\hline $14 \% \mathrm{Hv}+86 \% \mathrm{PS}$ & $14 \% \mathrm{Hv}+86 \% \mathrm{PS}$ & $14 \% \mathrm{Hv}+86 \% \mathrm{PS}$ & $14 \% \mathrm{Hv}+86 \% \mathrm{PS}$ & $14 \% \mathrm{Hv}+86 \% \mathrm{PS}$ \\
\hline $17 \% \mathrm{Hv}+83 \% \mathrm{PS}$ & $17 \% \mathrm{Hv}+83 \% \mathrm{PS}$ & $17 \% \mathrm{Hv}+83 \% \mathrm{PS}$ & $17 \% \mathrm{Hv}+83 \% \mathrm{PS}$ & $17 \% \mathrm{Hv}+83 \% \mathrm{PS}$ \\
\hline $20 \% \mathrm{Hv}+80 \% \mathrm{PS}$ & $20 \% \mathrm{Hv}+80 \% \mathrm{PS}$ & $20 \% \mathrm{Hv}+80 \% \mathrm{PS}$ & $20 \% \mathrm{Hv}+80 \% \mathrm{PS}$ & $20 \% \mathrm{Hv}+80 \% \mathrm{PS}$ \\
\hline $2 \% \mathrm{Hm}+98 \% \mathrm{PS}$ & $2 \% \mathrm{Hm}+98 \% \mathrm{PS}$ & $2 \% \mathrm{Hm}+98 \% \mathrm{PS}$ & $2 \% \mathrm{Hm}+98 \% \mathrm{PS}$ & $2 \% \mathrm{Hm}+98 \% \mathrm{PS}$ \\
\hline $5 \% \mathrm{Hm}+95 \% \mathrm{PS}$ & $5 \% \mathrm{Hm}+95 \% \mathrm{PS}$ & $5 \% \mathrm{Hm}+95 \% \mathrm{PS}$ & $5 \% \mathrm{Hm}+95 \% \mathrm{PS}$ & $5 \% \mathrm{Hm}+95 \% \mathrm{PS}$ \\
\hline $8 \% \mathrm{Hm}+92 \% \mathrm{PS}$ & $8 \% \mathrm{Hm}+92 \% \mathrm{PS}$ & $8 \% \mathrm{Hm}+92 \% \mathrm{PS}$ & $8 \% \mathrm{Hm}+92 \% \mathrm{PS}$ & $8 \% \mathrm{Hm}+92 \% \mathrm{PS}$ \\
\hline $11 \% \mathrm{Hm}+89 \% \mathrm{PS}$ & $11 \% \mathrm{Hm}+89 \% \mathrm{PS}$ & $11 \% \mathrm{Hm}+89 \% \mathrm{PS}$ & $11 \% \mathrm{Hm}+89 \% \mathrm{PS}$ & $11 \% \mathrm{Hm}+89 \% \mathrm{PS}$ \\
\hline $14 \% \mathrm{Hm}+86 \% \mathrm{PS}$ & $14 \% \mathrm{Hm}+86 \% \mathrm{PS}$ & $14 \% \mathrm{Hm}+86 \% \mathrm{PS}$ & $14 \% \mathrm{Hm}+86 \% \mathrm{PS}$ & $14 \% \mathrm{Hm}+86 \% \mathrm{PS}$ \\
\hline $17 \% \mathrm{Hm}+83 \% \mathrm{PS}$ & $17 \% \mathrm{Hm}+83 \% \mathrm{PS}$ & $17 \% \mathrm{Hm}+83 \% \mathrm{PS}$ & $17 \% \mathrm{Hm}+83 \% \mathrm{PS}$ & $17 \% \mathrm{Hm}+83 \% \mathrm{PS}$ \\
\hline $20 \% \mathrm{Hm}+80 \% \mathrm{PS}$ & $20 \% \mathrm{Hm}+80 \% \mathrm{PS}$ & $20 \% \mathrm{Hm}+80 \% \mathrm{PS}$ & $20 \% \mathrm{Hm}+80 \% \mathrm{PS}$ & $20 \% \mathrm{Hm}+80 \% \mathrm{PS}$ \\
\hline
\end{tabular}




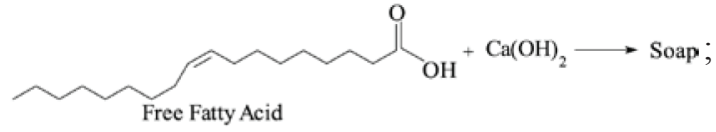

- An ester (Hv) which, in its basic medium, turns into carboxylate by saponification:

$$
\underset{\text { Esters }}{\mathrm{R}-\mathrm{C}^{\prime /}} \stackrel{\mathrm{O}-\mathrm{R}^{+}}{+}{ }^{+\mathrm{Ca}(\mathrm{OH})_{2}} \longrightarrow \text { Soap. }
$$

The carboxylate ion (R-COO-) is a compound of two parts (Fig. 6a):

- The polar carboxylate group (-COO-) that is easily surrounded by (polar) water molecules and establishes hydrogen bonds with them. This group constitutes the hydrophilic part (also called the hydrophilic head) of the carboxylate ion because this group has an affinity for water.

- The apolar alkyl group (R), the carbon chain of which is typically long. This group forms the hydrophobic part (called the hydrophobic tail or lipophilic part) of the carboxylate ion because this group has no affinity for water. However, it has an affinity for fatty substances, such as $\mathrm{R}$, that present a large number of apolar C-C and C-H bounds.

The carboxylate ion, with a hydrophilic part and a lipophilic part, is an amphiphilic species. In the presence of water, carboxylates form spherical aggregates or micelles (Fig. 6b).

The purpose of this test was to obtain quantitative information about the soap formation caused by contact between the pore solution and the oil. Dried and tared bottles were filled with a pore solution-oil mixture. They were agitated and left to stand for 1 minute. The filled bottles were then weighed to determine the amount of soap deposited on the walls. The weight of the soap $\left(W_{s}\right)$ was determined as follows:

$$
W_{s}=W_{(B, A f t e r)}-W_{(B, B e f o r e)},
$$

where $W_{B}$ and $W_{s}$ are the weight of the bottle and the soap, respectively.

\subsection{Measurement of zeta potential}

Zeta potential measurements were performed using a Zetasizer Nano ZS from Malvern Instruments. This device also measures the particle size, $\mathrm{pH}$ and conductivity,

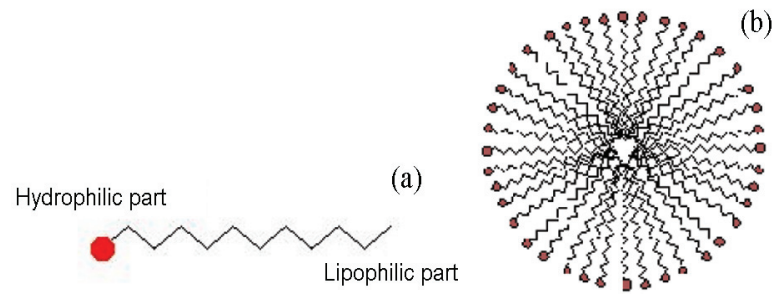

Fig. 6. Soap molecule (carboxylate ion) (a) and diagram of micelles (b) which are other parameters that affect the stability of emulsions. The measuring cell was a capillary U-shaped cell connecting two electrodes and filled with a dispersed solution (the interstitial medium containing soap). The medium was filtered using a cellulose nitrate membrane with a porosity of less than $10 \mu \mathrm{m}$ (the detection limit of the device) before being introduced into the measuring cell. After stabilization of the cuvette at $25{ }^{\circ} \mathrm{C}$, the measurement was started and repeated twice.

\section{Results and discussion}

\subsection{Recording of friction stress}

To understand the mechanisms at the concrete/oil/formwork interface as they relate to the paste volume, friction tests were conducted using a plan/plan tribometer. Figure 7 shows the recording of the tangential force and the friction coefficient as a function of time for different contact pressures for $\mathrm{C} 28$ without a release agent.

The results show that the curve shapes are similar regardless of the pressure. These graphs can be decomposed into two zones (Vanhove 2001):

- zone I displays a growth in friction stress due to the start-up time of the engine to catch up with gaps and the elastic response of the mechanical system.

- zone II reflects a stationary regime. Friction is nearly constant during the test. The stresses of static and dynamic friction are similar for this concrete/wall interface. The friction in this zone will be the friction that will be taken into account.

In addition, Figure 7 highlights the evolution of the friction coefficient as a function of test time. The results indicate that the friction coefficient decreases when the contact pressure increases. For these experimental conditions, its value is between 0.17 and 0.34 . However, the friction coefficient varies between 0 and 0.22 for selfconsolidating concrete (Proske 2007). This difference is explained by the rheological properties of this type of concrete and the loading method used in this study. In this case, the pressure was applied gradually from 0 to $80 \mathrm{kPa}$.

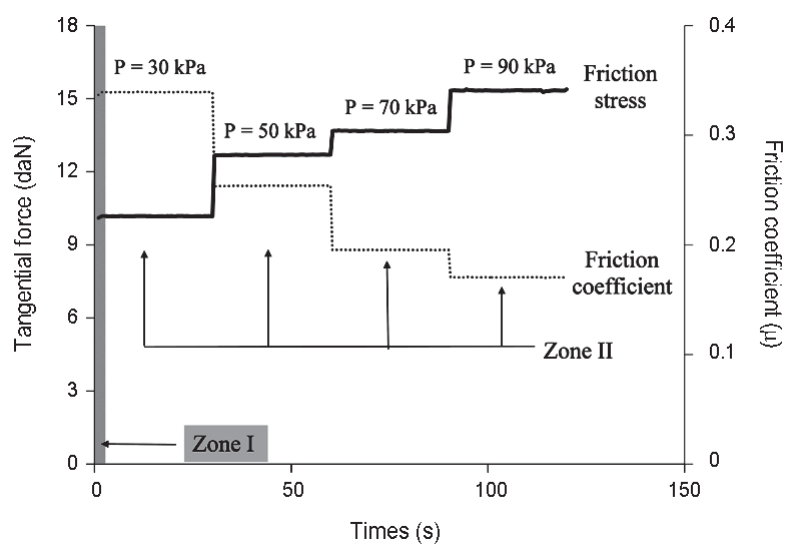

Fig. 7. Evolution of friction stress and friction coefficient as a function of time for $\mathrm{C} 28$ without a release agent 


\subsection{Friction at concrete/oil/formwork interface}

Figures 8, 9, 10, 11 and 12 illustrate the evolution of friction stress with contact pressure for both release agents ( $\mathrm{Hv}$ and $\mathrm{Hm}$ ).

Each point on these graphs represents an average of five points in the dynamic regime (zone II) of Figure 7. The results show that the presence of a release agent reduces the friction stress of the concrete close to the formwork wall. For example, friction decreases of approximately 16 to $39 \%$ for $\mathrm{C} 28$ and 55 to $70 \%$ for $\mathrm{C} 36$ are observed for the concrete/oil/formwork interface compared to the tangential stress of the interface without oil. For one concrete with $28 \%$ of paste, Libessart (2006) obtained a similar result.

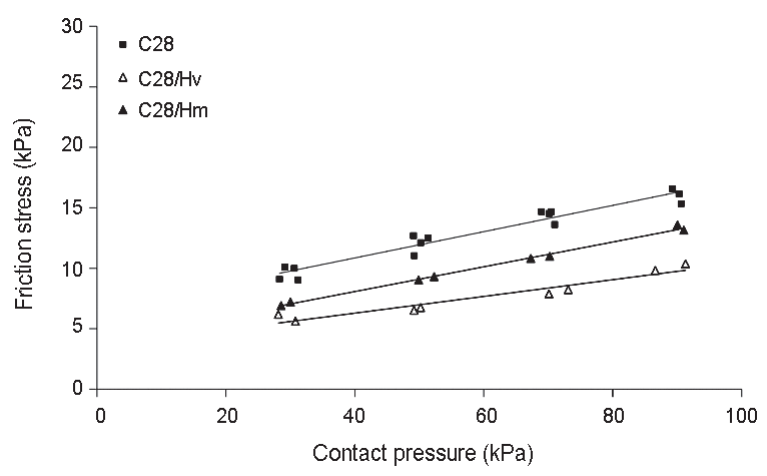

Fig. 8. Evolution of friction stress as a function of contact pressure for $\mathrm{C} 28$ with release agent

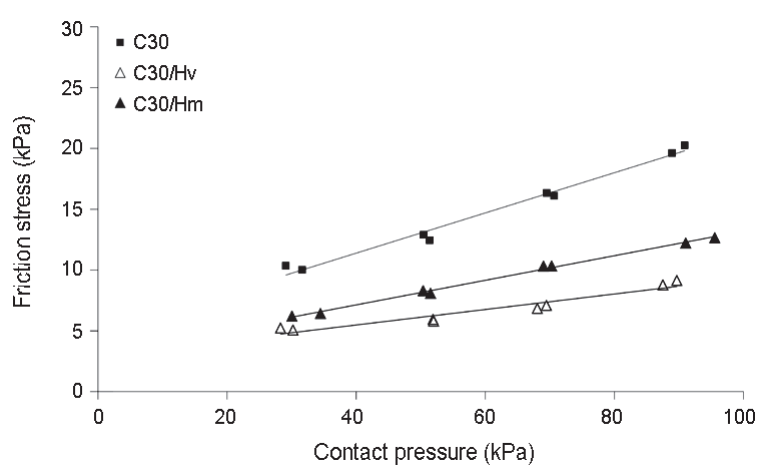

Fig. 9. Evolution of friction stress as a function of contact pressure for $\mathrm{C} 30$ with release agent

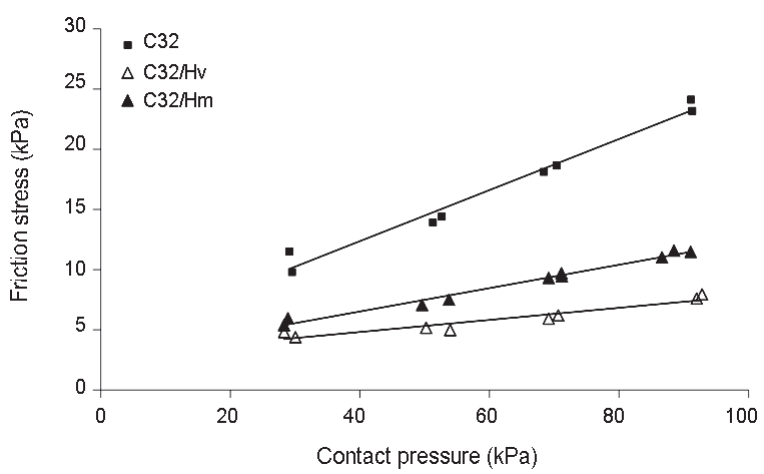

Fig. 10. Evolution of friction stress as a function of contact pressure for $\mathrm{C} 32$ with release agent

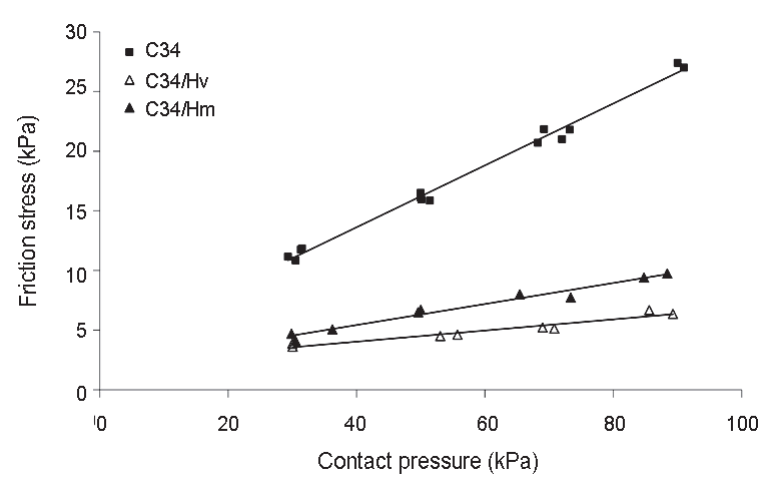

Fig. 11. Evolution of friction stress as a function of contact pressure for $\mathrm{C} 34$ with release agent

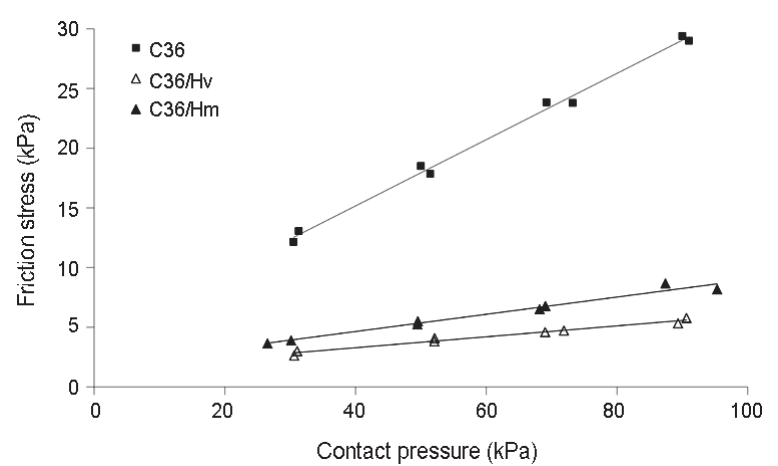

Fig. 12. Evolution of friction stress as a function of contact pressure for $\mathrm{C} 36$ with release agent

When the plate is moved, the friction between the cement grains and the metallic plate resists the displacement. The presence of a release agent on the metallic plate reduces the friction at the interface between the concrete and the wall. Oils prevent the penetration of fine cement and aggregate particles into the rough surface of the wall during the passage of fresh concrete, which minimizes adhesion and friction stress at the interface. In addition, the use of a release agent decreases capillary forces by reducing the ability of the plate to be wetted and increases the resistance to charge transfer.

The friction stress is less pronounced for $\mathrm{Hv}$, regardless of the paste volume of the concrete. This oil has a chemical effect due to saponification and salification reactions with an organization in a double layer oil/soap at the concrete/oil/ formwork interface (Libessart 2006; Hart 1994; Hurd 1996). This configuration is favourable to the reduction of friction. However, Hm has a physical effect, due to its hydrophobic nature, that prevents the concrete from adhering to the formwork. The results for the oil film have been shown that the effectiveness of this physical barrier depends on its thickness (Libessart 2006; Hart 1994; Hurd 1996).

\subsection{Oil film thickness and interface composition}

Figures 13 and 14 show the evolution of the reduction ratio of oil film as a function of contact pressure after the passage of fresh concrete for both oils. 


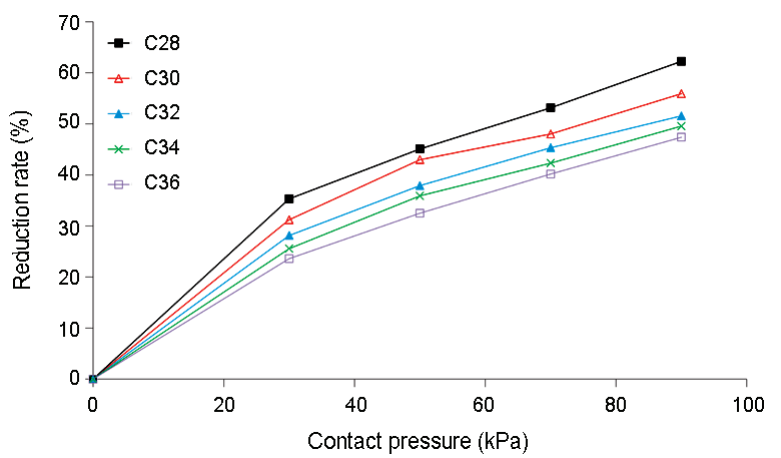

Fig. 13. Variation in oil film as a function of contact pressure for $\mathrm{Hv}$

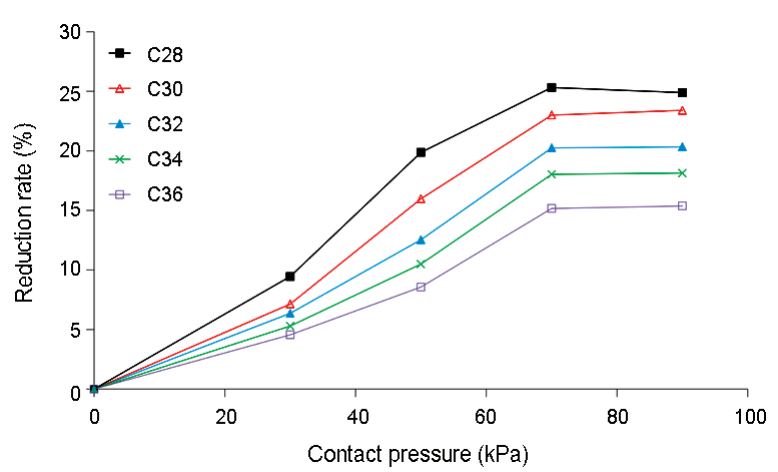

Fig. 14. Variation in oil film as a function of contact pressure for $\mathrm{Hm}$

The results indicate that the oil film thickness is reduced when the contact pressure increases. This phenomenon is more pronounced for Hv. These results are consistent with those obtained by Libessart (2006) for a single concrete with a $28 \%$ paste volume. Bouharoun (2011) obtained similar results for concretes at different paste volume.

The oil film thickness is reduced less when the paste volume increases. In the case of concrete with a low paste volume, the concrete at the interface does not contain enough fines to prevent the contact of aggregates with the metal surface. This phenomenon causes ruptures of the oil film at the interface and a more substantial loss of the oil film. Moreover, after the passing of fresh concrete, the film thickness of $\mathrm{Hv}$ is reduced by approximately 40 to $50 \%$ from its initial thickness, depending on the paste volume. This phenomenon is accentuated for concretes with low paste contents. However, a reduction of approximately 10 to $20 \% \mathrm{~m}$ compared to the initial film thickness is observed in the case of Hm. In addition, at contact pressures above $50 \mathrm{kPa}$, the film thickness remains constant.

These observations suggest that $\mathrm{Hm}$ reduces friction by reducing resistance to sliding of fresh concrete on formwork walls. Despite the significant reduction of film thickness of $\mathrm{Hv}$, the frictions at the interface are lower compared to Hm. These results confirm that other mechanisms are involved in limiting friction stress in the vicinity of formwork (Hart 1994; Bouharoun 2011).
The composition of interstitial mediums was estimated from the pore solution at the interface and the percentage of reduction of the oil film thickness. The proportion of oil in interstitial mediums was calculated using following equation:

$$
\% H=\frac{e \times S_{c}}{e \times S_{c}+M_{P S}} \times 100,
$$

where: $\% H$ is the percentage of oil thickness reduction, e is the thickness of oil; $S_{c}$ is the contact surface between the concrete and formwork $\left(113.04 \mathrm{~cm}^{2}\right)$, and $M_{P S}$ is the mass of pore solution at the concrete/formwork interface.

The percentage of pore solution $(P S)$ is determined as follows:

$$
\% P S=100-\% H .
$$

Table 5 provides information on the composition of the interstitial medium of each concrete.

The results indicate that as the paste volume and contact pressure increase, the percentage of pore solution constituting interstitial mediums at the interface decreases. This phenomenon is most likely linked to the high fines content in the case of concretes with high paste volumes, which limit the migration of free water in fresh concrete toward the formwork under pressure. In conclusion, the oil content in interstitial mediums at the interface increases when the paste volume of the concrete increases.

Table 5. Composition of real interstitial mediums of each

\begin{tabular}{|c|c|c|c|c|}
\hline & Pressure $(\mathrm{kPa})$ & PS (\%) & Hv $(\%)$ & $\operatorname{Hm}(\%)$ \\
\hline \multirow{4}{*}{ B28 } & 30 & 97.54 & 2.46 & 0.65 \\
\hline & 50 & 97.51 & 2.49 & 1.09 \\
\hline & 70 & 97.09 & 2.91 & 1.38 \\
\hline & 90 & 91.22 & 8.78 & 3.51 \\
\hline \multirow{4}{*}{ B30 } & 30 & 97.22 & 2.78 & 0.63 \\
\hline & 50 & 97.17 & 2.83 & 1.05 \\
\hline & 70 & 96.54 & 3.46 & 1.65 \\
\hline & 90 & 90.32 & 9.68 & 4.05 \\
\hline \multirow{4}{*}{ B32 } & 30 & 96.66 & 3.34 & 0.75 \\
\hline & 50 & 96.59 & 3.41 & 1.12 \\
\hline & 70 & 95.69 & 4.31 & 1.92 \\
\hline & 90 & 89.66 & 10.34 & 4.07 \\
\hline \multirow{4}{*}{ B34 } & 30 & 95.46 & 4.54 & 0.93 \\
\hline & 50 & 95.06 & 4.94 & 1.44 \\
\hline & 70 & 94.5 & 5.5 & 2.34 \\
\hline & 90 & 84.99 & 15.01 & 5.49 \\
\hline \multirow{4}{*}{ B36 } & 30 & 94.95 & 5.05 & 0.97 \\
\hline & 50 & 94.58 & 5.42 & 1.43 \\
\hline & 70 & 92.45 & 7.55 & 2.85 \\
\hline & 90 & 84.7 & 15.3 & 4.96 \\
\hline
\end{tabular}
concrete 


\subsection{Study of interstitial mediums}

\subsubsection{Soap quantity}

Evaluating the quantity of soap formed with the both oils is very important because it determines the ability of the release agent to produce a chemical effect in the vicinity of the formwork wall. Figure 15 shows the amount of soap formed as a function of the oil content.

The results show that the amount of soap in the interstitial mediums increases for high oil contents. In addition, $\mathrm{Hv}$ generates more soap than $\mathrm{Hm}$. This difference can be explained on the one hand by the low acid index $(1 \mathrm{mg} \mathrm{KOH} / \mathrm{g}$ ) of $\mathrm{Hm}$, and on the other hand by the ability of vegetable esters to form soaps.

Increasing the oil percentage in the interstitial medium promotes the formation of soap. The nature and quantity of oil therefore have an effect on the soap amount produced. These observations show that soap formation occurs by saponification from vegetable ester and by salification from fatty acids.

This interesting result suggests that concretes with high paste volumes produce more soap at the interface with low oil contents, because oil participates in the formation of interstitial mediums in the vicinity of formwork. Moreover, the origin of the pore solution has an important influence on the amount of soap formed in the vicinity of formwork.

\subsubsection{Zeta potential of interstitial mediums}

Figure 16 shows the evolution of zeta potential as a function of oil content.

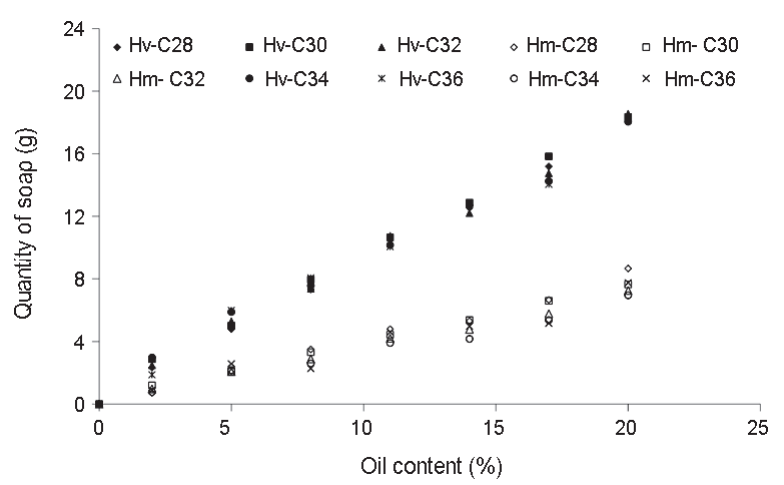

Fig. 15. Evolution of soap quantity as a function of oil content

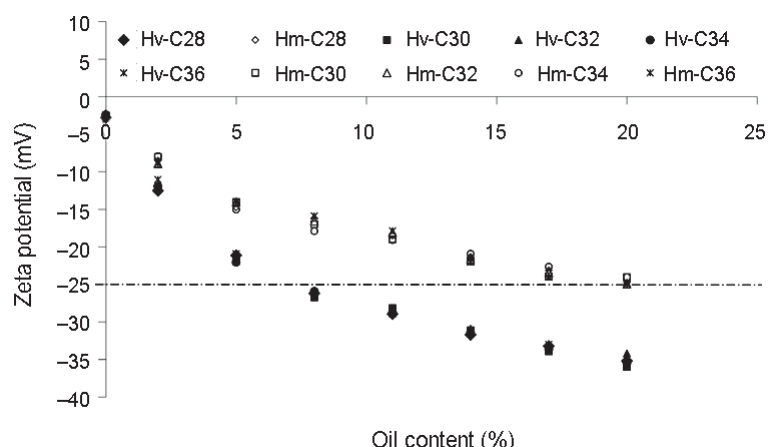

Fig. 16. Evolution of potential zeta as a function of oil content
A negative zeta potential (PZ) indicates an overall negative charge. In commercial emulsions, it is the additives associated with the surfactant used that create a negative $\mathrm{PZ}$, in the range of -40 to $-50 \mathrm{mV}$ (Husson et al. 2003). According to Washington (1992) and Washington et al. (1989), the zone of instability of an emulsion is between $-25 \mathrm{mV}$ and $+25 \mathrm{mV}$.

The results show that the zeta potential depends directly on the nature of the oil involved in the emulsion. Whatever the concentrations of oil, the zeta potential is higher (in absolute value) for $\mathrm{Hv}$ than for $\mathrm{Hm}$. This suggests a greater stability of emulsions with $\mathrm{Hv}$ compared to $\mathrm{Hm}$. This stability is observed beginning at $8 \%$ oil content for $\mathrm{Hv}$ and $20 \%$ oil content for Hm. Regardless of the oil content, interstitial mediums are not stable and present a dephasing of emulsions. In addition, the results indicate that the composition of the concrete does not influence the evolution of the zeta potential of interstitial mediums. Similar results were obtained by Husson et al. (2003) on the formation of emulsions. After the contact release agent/pore solution, the interstitial mediums form an emulsion in the vicinity of the formwork.

Moreover, it is observed that the zeta potential increases with oil content, promoting a stable organization of the medium. The soap formed in the interstitial medium thus has surfactant properties involved in the formation and stability of the emulsion. Thus, interstitial mediums are formed in the presence of concrete with a high volume of paste.

\subsubsection{Contact angle and surface tension}

The surface tension and contact angle results for the pore solution and the interstitial mediums are given in Figures 17 and 18. It is important to remember that the hydrophobicity of surfaces is more efficient when the contact angle and surface tension are high. The results show that the surface tension and contact angle are not influenced by the nature of the pore solution (i.e. the paste volume).

The formation of soap in mediums decreases the surface tension and contact angle, reflecting a certain affinity with the oil film. This result shows also that the surfactant power of soap formed tends to lower the

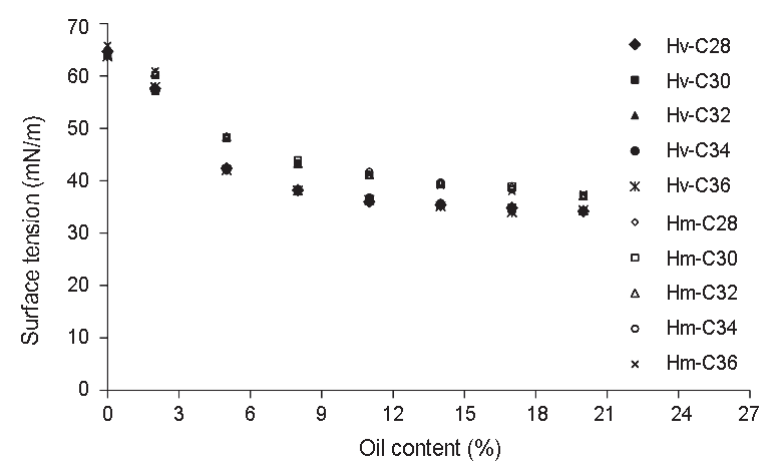

Fig. 17. Evolution of surface tension as a function of oil content 


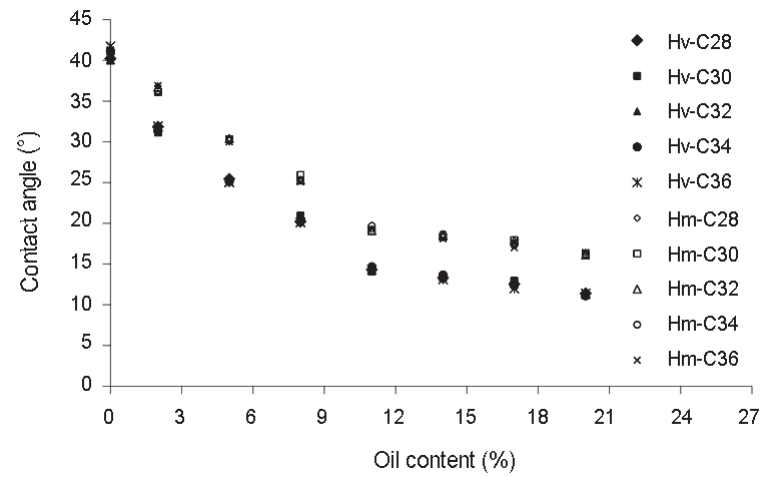

Fig. 18. Evolution of contact angle as a function of oil content

surface tension and contact angle between interstitial mediums and the oiled plate.

In addition, the results show that an increase in the oil content reduces the surface tension and contact angle of interstitial mediums. This reduction is more pronounced for Hv. Kozlovtsev et al. (2003) studied the wettability of five release agents on formwork surfaces as a function of their origin and time. They showed that vegetable oils provide better wettability (a low contact angle). These similar results confirmed that the vegetable oils have a better wettability than the mineral oils.

Indeed, when the formwork surface is covered by an oil layer ( $\mathrm{Hv}$ and $\mathrm{Hm}$ ), its surface is not made completely hydrophobic by the presence of surfactants (soaps) which emulsify a portion of the two phases (oil and pore solution). These molecules promote the spreading of interstitial mediums on the surface of the metallic plate (Michalski et al. 2000, 1998), resulting in a reduction in the contact angle and surface tension. Courarda et al. (2011) measured the contact angle and the surface tension on the metal substrate at $20{ }^{\circ} \mathrm{C}$ for mixtures composed of distilled water and two release agents. Despite this difference in the composition of interstitial mediums, their results were similar to those obtained in the case of our study. But in the present study, the interstitial mediums used are similar to those formed in the formwork on the construction sites while the tests performed by the authors were limited to the distilled water.

\subsection{Interfacial phenomena}

The results obtained from the physicochemical study of interstitial mediums showed that the formation of soap is greater in the case of $\mathrm{Hv}$, which yields better stability and therefore higher efficiency of the interstitial emulsion. $\mathrm{Hm}$ is more easily emulsified by soap than $\mathrm{Hv}$ because it does not form a soap film. However, the soap film does not create on oil film as in the case of Hv, due to deterioration of the oil film by solubilization in the presence of soaps at the interface (Rabinovitch et al. 1984). The correlations established between the ability to reduce friction and physicochemical measurements make it possible to identify two processes that intervene close to the formwork:
- The emulsification of hydrocarbons ( $\mathrm{Hm})$ and esters (Hv) by the soaps formed; and

- The transformation of esters into soap (saponification), catalyzed by fatty acids (acidifiers) present in the oil, which are themselves turned into soap (salts of fatty acids).

In the case of $\mathrm{Hv}$, the interface forms two layers (Rabinovitch et al. 1984). The ester molecules, owing to their polarity, adsorb preferentially on the metal wall of the formwork by chemical interactions (Jacquet et al. 1974). The calcium carboxylates orient themselves toward the hydrophilic concrete. In addition, the abundant formation of soap from ester improves lubricant performance at the concrete/oil/formwork interface due to the soap layer formed on the oil film.

In the case of Hm, micelles between carboxylates and hydrocarbons molecules are formed at the interface by alteration of the film. Calcium soap, which has low solubility in water, thus acts as a detergent (Michalski et al. 1998) that partially solubilizes the film and diminishes the performance of the oil film. This performance loss is compensated by the high oil content in interstitial mediums, which favors the formation of a stable interfacial emulsion oil/soap. Thus, a high content of emulsified oil in interstitial mediums facilitates sliding of the fresh concrete on the formwork, thanks to the formation of soap at the interface for both types of oil.

Dhir et al. (1996) highlighted the mechanisms involved close to the formwork during the concrete pouring. The remove of the formwork is accomplished thanks to a chemical or a physical reaction or a combination of both. The phenomena shown in their study are in accordance with our results. The physical reaction is characterized by the creation of an interfacial film between the formwork and the concrete. The chemical reaction results in the formation of soap between the alkali component of the cement and fatty acid in the oil-based release agent. The reduction in friction stress observed in our study was due to both of these phenomena.

Furthermore, when the paste volume increases, the friction stress decreases (Figs 19 and 20). This result confirms that the friction behaviour depends on the quantity of interstitial material. The volume of paste influences the formation of interstitial emulsion. In fact, when the paste

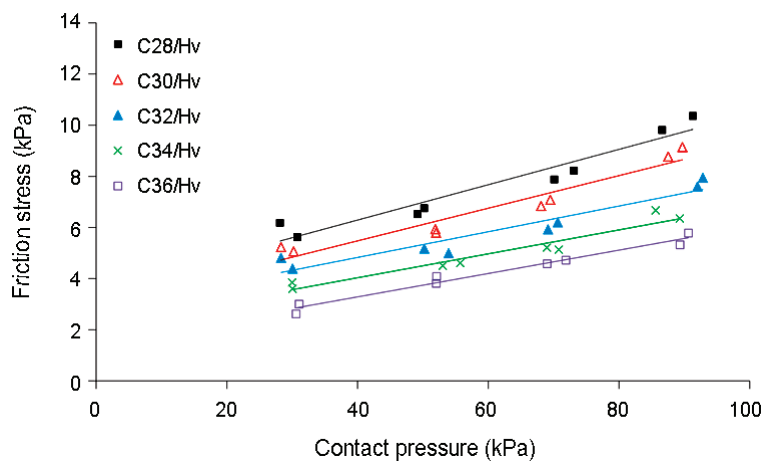

Fig. 19. Evolution of friction stress for $\mathrm{Hv}$ 


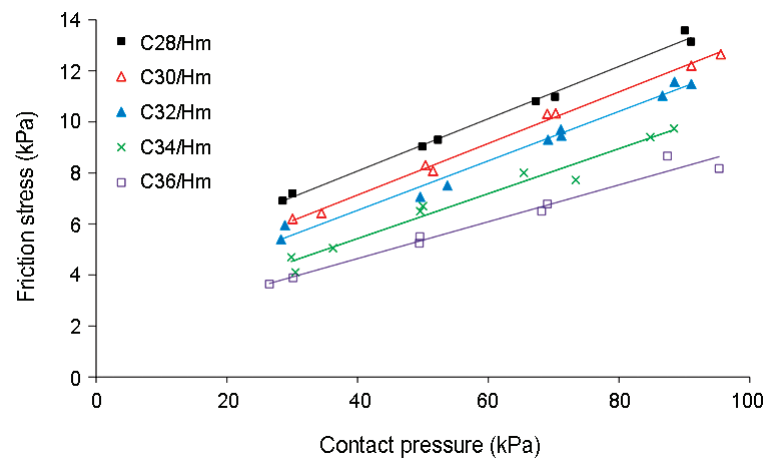

Fig. 20. Evolution of friction stress for $\mathrm{Hm}$

volume increases, the amount of concrete pore solution at the interface is reduced by congestion of fine particles at the interface that limit the migration of free water to the formwork wall (Bouharoun 2011). Thus, concretes with high paste volumes will form interstitial mediums with high oil contents, which results in the production of more soap and better emulsification of the interface. All the phenomena mentioned above contribute to reduced friction stress, depending on the amount of soap (for Hv) or emulsion interfacials (for both oils).

\section{Conclusions}

This study was conducted to identify the parameters that influence the properties at the concrete/oil/formwork interface during concrete pouring. The following conclusions were drawn from the results of this study:

- Regardless of the type of release agent involved, an increase in the concrete paste volume reduces the friction stress and the pore solution at the concrete/ formwork interface;

- The use of Hv and increasing oil content produce more soap and stabilize emulsified interstitial mediums;

- The thickness of the oil film is not the only factor that governs the constraints of friction at the interface. The existence of an emulsified phase that results from reducing the interfacial tension (contact angle and surface tension) is another key parameter that can explain the friction behaviour;

- Regardless of the concrete paste volume, the friction between fresh concrete and formwork is reduced to a greater degree with $\mathrm{Hv}$, thanks to the reduction of the film of oil that is transformed into soap rather than into an emulsion. Saponification and salification reactions occur at the interface. Thus, an organized structure of soap and oil layers is effective in lubricating the interface. However, the performance of $\mathrm{Hm}$ is improved by high oil content in interstitial mediums in the vicinity of formwork.

The chemical interactions that would occur in the presence of a superplasticizer in the concrete at different dosages would be interesting to study. To better understand the effects of these interface phenomena, research on the quality of concrete surfaces is recommended.

\section{References}

Amziane, S.; Ferraris, C. F.; Koehler, E. P. 2005. Measurement of rheological properties of fresh concrete using a mixing truck, Journal of Research of the National Institute of Standards and Technology 110(1): 393-399. http://dx.doi.org/10.6028/jres.110.006

Baty, G.; Reynolds, R. 1997. Release agents - how they work, ACI Concrete International 19(10): 52-54.

Bouharoun, S. 2011. Comportement tribologique des huiles de décoffrage à l'interface béton/coffrage - influence de la formulation du béton: $\mathrm{PhD}$ thesis. University of Artois, Béthune (in French).

Courarda, L.; Goffinet, C.; Migeotte, N.; Martin, M.; Pierard, J.; Polet, V. 2012. Influence of the reuse of OSB and marine plywood formworks on concrete surface aesthetics, Materials and Structures 45(8): 1331-1343. http://dx.doi.org/10.1617/s11527-012-9835-0

Courarda, L.; Michela, F.; Martin, M. 2011. The evaluation of the surface free energy of liquids and solids in concrete technology, Construction and Building Materials 25(1): 260-266. http://dx.doi.org/10.1016/j.conbuildmat.2010.06.030

De Brito, J.; Dos Santos, R.; Branco, F. A. 2000. Evaluation of the technical performance of concrete vegetable oil based release agents, Materials and Structures 33(228): 262-269. http://dx.doi.org/10.1007/BF02479336

De Larrard, F. 1999. Concrete mixture proportioning: a scientific approach. $1^{\text {st }}$ ed. London: Spon Press. 440 p.

De Larrard, F.; Ferraris, C. F.; Sedran, T. 1998. Fresh concrete: a Herschel-Bulkley material, Materials and Structures 31(7): 494-498. http://dx.doi.org/10.1007/BF02480474

Dhir, R.; Dyer, T. 1996. Concrete in the service of mankind, concrete for environment enhancement and protection. $1^{\text {st }}$ ed. CRC Press. 735 p.

Ferraris, F. C. 1999. Measurement of rheological properties of high performance concrete: state of the art, Journal of Research of the National Institute of Standards and Technology 104(5): 461-478. http://dx.doi.org/10.6028/jres.104.028

Ferraris, C. F.; De Larrard, F. 1998. Modified slump test to measure rheological parameters of fresh concrete, Cement, Concrete, and Aggregates 20(20): 241-247.

Gram, H. E. 2004. Discussion of possible reasons surface defects of SCC, Betonwerk und Fertigteil-Technik 70(8): 28-33.

Graubner, C. A.; Boska, E.; Motzko, C.; Proske, T.; Dehn, F. 2012. Formwork pressure induced by highly flowable concretes - design approach and transfer into practice, Structural Concrete 13(1): 51-60. http://dx.doi.org/10.1002/suco.201100012

Hart, I. 1994. Concrete release agent, associated materials and surface finishes, Concrete 28(2): 33-34.

Husson, E.; Crauste-Manciet, S.; Hadj-Salah, E.; C. Séguier, J.; Brossarda, D. 2003. Compatibility of parenteral drugs with commercialized total parenteral admixtures: injection of drug inside the admixtures, Nutrition Clinique et Métabolisme 17(1): 8-14. http://dx.doi.org/10.1016/S0985-0562(03)00006-2

Hurd, M. 1996. Choosing and using a form release agent, Concrete Construction 41(10): 732-736.

Jacquet, M.; Georges, J. M.; Mathia, T. 1974. Adsorption sur un solide d'un composé polaire à partir d'une solution non polaire [Adsorption on a solid of a polar compound from a non-polar solution], Revue de l'institut Français du Pétrole 29(5): 715-729.

Koehler, E. P. 2004. Development of a portable rheometer for portland cement concrete: $\mathrm{PhD}$ thesis. University of Texas, Austin. 
Koehler, E. P.; Fowler, D. W.; Ferraris, C. F.; Amziane, S. 2006. A new portable rheometer for fresh self-consolidating concrete, ACI Materials: Special Publication 233: 97-116.

Kozlovtsev, A. P.; Zhumlyakova, M. A.; Zanozina, I. I.; Larionova, I. G.; Polishchuk, N. V. 2003. Process oils for forms for concrete metalwork, Chemistry and Technology of Fuels and Oils 39(3): 130-132. http://dx.doi.org/10.1023/A:1024579323318

Kwon, S. H.; Phung, Q. T. H.; Park, Y.; Kim, J. H.; Shah, S. P. 2011. Effect of wall friction on variation of formwork pressure over time in self-consolidating concrete, Cement and Concrete Research 41(1): 90-101. http://dx.doi.org/10.1016/j.cemconres.2010.09.009

Laskar, A. I.; Talukdar, S. 2009. Rheology-based approach for workability characterization of high-performance concrete, Canadian Journal of Civil Engineering 36(7): 1239-1244. http://dx.doi.org/10.1139/L09-058

Libessart, L. 2006. Influence de la composition des agents de démoulage à l'interface coffrage/béton - Impact sur l'esthétique des parements en béton [Influence of the composition of release agents at the formwork/concrete interface - Impact on the aesthetics of concrete surfaces]: $\mathrm{PhD}$ thesis. Béthune, University of Artois (in French).

Michalski, M. C.; Desobry, S.; Hardy, J. 1998. Adhesion of edible oils and food emulsions to rough surfaces, $L W T-$ Food Science and Technology 31(5): 495-502.

Michalski, M.; Saramago-Benilde, J. V. 2000. Static and dynamic wetting behavior of triglycerides on solid surfaces, Journal of Colloid and Interface Science 227(2): 380-389. http://dx.doi.org/10.1006/jcis.2000.6869

NF EN 12350-2. Testing fresh concrete. European Committee for Standardization, Brussels, 1999.

NF EN 197-1 Cement - part 1: compositions. Specifications and conformity criteria for common cement. European Committee for Standardization, Brussels, 2000.

Ngo, T. T.; Kadri, E. H.; Bennacer, R.; Cussigh, F. 2010. Use of tribometer to estimate interface friction and concrete next term boundary layer composition during the fluid "concrete pumping", Construction and Building Materials 24(7): 1253-1261.

http://dx.doi.org/10.1016/j.conbuildmat.2009.12.010
Ngo, T. T.; Kadri, E. H.; Cussigh, F.; Bennacer, R. 2011. Measurement and modeling of fresh concrete viscous constant to predict pumping pressures, Canadian Journal of Civil Engineering 38(8): 944-956. http://dx.doi.org/10.1139/111-058

Proske, T. 2007. Frischbetondruck bei Verwendung von Selbstverdichtendem Beton - Ein wirklichkeitsnahes Modell zur Bestimmung der Einwirkungen auf Schalung und Rüstung [Concrete pressure with the use of self-compacting concrete - A realistic model to determine the effects on formwork and scaffolding]: PhD thesis. Technische Universität Darmstadt, Darmstadt (in German).

Proske, T.; Graubner, C. A. 2010. Formwork pressure of highly workable concrete - experiments focused on setting, vibration and design approach, in Design, production and pacement of self-consolidating concrete. Springer Netherlands: RILEM Bookseries, 255-267.

Rabinovitch, E. B.; Lacatus, E.; Summers, J. W. 1984. The lubrification mechanism of calcium stearate/paraffin wax systems in PVC compounds, Journal of Vinyl and Additive Technology 6(3): 98-103. http://dx.doi.org/10.1002/vnl.730060303

Thompson, M. S. 1969. Blowholes in concrete surfaces, Concrete Society 2(3): 64-66.

Vanhove, Y. 2001. Contribution à l'étude du frottement d'un béton autoplaçant contre une surface métallique application aux poussées contre les coffrages [Contribution to the study of friction of self-compacting concrete against a metal surface - application to pressure against the formwork]: $\mathrm{PhD}$ thesis. University of Artois, Béthune (in French).

Washington, C. 1992. The electrokinetic properties of phospholipid stabilized fat emulsions VI. Zeta potentials of Intralipid 20\% in TPN mixtures, International Journal of Pharmaceutics 87(1-3): 167-174. http://dx.doi.org/10.1016/0378-5173(92)90240-3

Washington, C.; Chawla, A.; Christy, N.; Davis, S. 1989. The electrokinetic properties of phospholipid-stabilized fat emulsions, International Journal of Pharmaceutics 54(3): 191-197. http://dx.doi.org/10.1016/0378-5173(89)90096-3

Samir BOUHAROUN. Assistant Professor of Civil Engineering at the Department of Civil Engineering at Polytech'Nantes of Nantes University. PhD in Civil Engineering from Artois University in 2011. Main research interests include rheology and tribology of fresh concrete, chemical interactions between release agent and fresh concrete, hydration rate on cement, recycling of fiber-cement waste, durability of concretes. 